\title{
Leftists possess more national consensus in Europe in one of two datasets
}

\author{
Mark J. Brandt \\ Anthony Aron \\ Megan Parker \\ Cristina Rodas \\ Megan Shaffer \\ Michigan State University
}

Please address correspondence to Mark Brandt at brandt15@msu.edu

Draft Date: 12 April 2021

This paper has not undergone peer review. Feedback is welcome. Please cite, but cite with care. Acknowledgements: We thank Ben Chandler for his help planning the study. 


\begin{abstract}
A regularity in US American politics is that liberals have more policy consensus than do conservatives, and both ideological groups have more consensus than moderates (Ondish \& Stern, 2018). The idea is that conservatives' local conformity paradoxically results in less consensus than liberals at the national level. If this is the case, then the liberal consensus effect should also be observed in other countries. We test this using data from Europe. In the European Social Survey (Country $\mathrm{N}=38, \mathrm{~N}=376,129$ ) we find that on average leftists have more consensus than do rightists; however, we do not find this using the Eurobarometer (Country $\mathrm{N}=$ $18, \mathrm{~N}=375,830)$. In both data sources we also observe variation in ideological differences between countries. These results suggest that there is a liberal/leftist consensus effect that can be found in Europe and the United States, but there are also exceptions.
\end{abstract}




\section{Leftists possess more national consensus in Europe in one of two datasets}

A key task in politics is to build consensus within political factions. Such consensus can be leveraged to pursue common political and social goals. Some groups may be better equipped or motivated to reach consensus, such as people with authoritarian tendencies who desire oneness and sameness (Stenner, 2005), or groups with homogenous backgrounds, such as Republicans in the United States (Mason, 2018). Perhaps surprisingly given this, one robust regularity in U.S. American politics is that liberals have more political consensus than do conservatives at the national level (Ondish \& Stern, 2018). And both groups have more consensus than do moderates. For simplicity, we refer to this pattern of results as the liberal consensus effect. We test if the effect can be found in Europe and if there is variation in the effect across countries.

\section{Liberal Consensus Effect}

Ondish and Stern (2018) test if people in the United States who identify as liberal, conservative, or moderate had the most consensus at the national level. They used the General Social Survey and the American National Election Studies, which allowed them to answer this question using over 80,000 people, 400 political issues, and across approximately 40 years. The results indicate that on a national level, liberals experience more consensus than conservatives. They also found that liberals and conservatives both hold greater consensus than do political moderates. They found that even when taking into account and adjusting for other demographic factors such as education, gender, or ethnicity, these results remain consistent. Ondish and Stern (2018) adopted a “one-with-many” design from the Social Relations Model (Kenny, Kashy, \& Cook, 2006) to estimate consensus within ideological groups. Studies using less sophisticated estimates of consensus have found similar results (e.g., Ellis \& Stimson, 2012; Feldman \& 
Johnston, 2014; Lupton, Myers, \& Thornton, 2017). This effect has been described as a robust regularity in U.S. politics and in the study of belief systems (Brandt \& Sleegers, 2021).

Ondish and Stern (2018) explain the liberal consensus effect by drawing on research about the psychological differences between liberals and conservatives. They start with the assumption that conservatives are motivated to align themselves with others that are like-minded and to build group cohesion. This is consistent with findings that conservatives in the United States score higher on measures of need for order, certainty, and predictability than do liberals (Jost, Sterling, \& Stern, 2017). It is also consistent with conservatives' tendency to endorse moral values that prioritize the ingroup (Graham, Haidt, \& Nosek, 2009) and to engage in more ideologically homogeneous Twitter networks (Barberá, Jost, Nagler, Tucker, \& Bonneau, 2015; Boutyline \& Willer, 2017). Conversely, liberals tend to be more accepting of uncertainty (Jost et al., 2017) and have a higher motivation for uniqueness (Stern, West, \& Schmitt, 2014). The authors also assume that when conservatives seek sources of information, they turn towards more local and immediate groups (e.g., friends, church, community organizations; Jost, Ledgerwood, \& Hardin, 2008).

Based on these two assumptions, the authors reason that when conservatives create consensus, they do so at a more local level than at a national level. When there is more consensus within local contexts and communities, it may shift the focus away from potential consensus at the national level (cf. Henrich \& Boyd, 1998). This leads conservatives to have less consensus than liberals at the national level. That is, Ondish and Stern (2018) suggest that conservatives' motivations for consensus at a local level leads to less consensus than liberals at the national level. This is consistent with the findings of their two studies that showed that liberals have more consensus than conservatives at the national level in the United States. 


\section{Leftist Consensus Effect in Europe?}

For reasons of historical happenstance, ideological identification in terms of liberal and conservative is not generally used and typically means something different in the European context. ${ }^{1}$ Instead, the political psychological literature on ideological identification in Europe has focused on identification with the left and the right, where the left is thought to share psychological and value similarities with US American liberals and the right is thought to share psychological and value similarities with US American conservatives (Caprara \& Vecchione, 2018; Chirumbolo, Areni, \& Sensales, 2004; Thorisdottir, Jost, Liviatan, \& Shrout, 2007). If Ondish and Stern's reasoning is accurate, we expect to find a leftist consensus effect in Europe, especially in Western Europe, that mimics the liberal consensus effect in the United States.

We predict there will be a leftist consensus effect because the motivations associated with ideological identification in the United States also tend to be associated with ideological identification in Europe (e.g., Chirumbolo, Areni, \& Sensales, 2004). For example, rule following and traditionalism are associated with right-wing identification in a variety of European countries (Thorisdottir, Jost, Liviatan, \& Shrout, 2007).

Importantly, the European context that appears to be the most similar to the United States is Western Europe. Since World War II, and despite their differences, Western Europe and the United States have shared political experiences and ideas with democracy, change, and addressing inequality. Eastern Europe, however, had a divergent historical path, which included the experience of communism and a totalitarian state. Such experiences appear to impact the meaning of "left" and "right" in these countries (Bauer et al, 2017) and how psychological

\footnotetext{
${ }^{1}$ Liberal in the European context, for example, often applies to center-right parties who have liberal (i.e. open, freemarket) economic policies (Knutsen, 1998). For a background on ideological terms in America, see Ellis and Stimson (2012).
} 
motivations and values are associated with ideological identification (e.g., Jost et al., 2009;

Kossowska \& van Hiel, 2003). For example, the link between need for security and right-wing identification appears to be negative in Eastern Europe and positive in Western Europe

(Thorisdottir et al., 2007; see also Malka et al., 2014).

Of course it is also possible that there is no leftist consensus effect in Europe, or at the least, the leftist consensus effect only emerges in select countries. For example, cross-cultural studies of the association between threat and political identities shows large differences between countries that were not readily explained by a difference between Western and Eastern Europe (Brandt et al., 2021). Although threat and ideology is a different topic than ideological national consensus, it may be indicative of broader heterogeneity in the psychology of ideological identification in different countries. More directly, work finds that the values of leftists and rightists in Europe are more heterogenous than the values of moderates and the values of leftists tend to be more heterogenous than the values of rightists (Hanel, Zarzeczna, \& Haddock, 2019; Van Hiel, 2012). This work suggests that there may be a "leftists dissensus" effect or a "moderate consensus" effect in Europe rather than a leftist consensus effect.

There is also some indirect evidence for a leftist consensus effect in Europe. One study examined the ideological identifications of people with different combinations of progressive and conservative attitudes on economic and cultural issues (Gidron, in press). They found that people with both progressive economic and cultural attitudes were more left-wing. Conversely, people with both conservative economic and cultural attitudes were more right-wing. Importantly, people with at least one conservative set of stances on either economic or cultural issues were more likely to be right-wing. This suggests that people who are left-wing tend to 
have more attitude consensus because there are more combinations of attitudes that are associated with people seeing themselves as right-wing.

\section{The Current Study}

We test for a leftist consensus effect - a conceptual replication of Ondish and Stern (2018) - using two large datasets that cover over 35 countries and several decades. For each country and survey wave, we follow the methodological approach of Ondish and Stern to calculate consensus for leftists, rightists, and moderates. We first estimate the average difference between ideological groups across countries and waves, expecting to find that leftists have more consensus than rightists. Then we estimate if there is variation in these effect between countries (cf. Bolger, Zee, Rossignac-Milon, \& Hassin, 2019; Whitsett \& Shoda, 2014). Finally, we attempt to explain that variation by testing if the leftist consensus effect is more prominent in Western Europe compared to Eastern Europe. Data and code can be found here:

\section{https://osf.io/yktze/?view_only=7d1b672f81654fbab3eb4efda1b35375}

\section{Method}

\section{Data \& Procedures}

We used data from the European Social Survey (ESS; European Social Survey, 20022018) and the Eurobarometer (EB) Trend file (Schmitt \& Scholz, 2005). The ESS fielded surveys every two years between 2002 and 2018 ( 9 surveys in total; Country $\mathrm{N}=38, \mathrm{~N}=$ 376,129). The EB included multiple surveys per year between 1982 and 2002 (33 surveys in total; Country $\mathrm{N}=18 ; \mathrm{N}=375,830) .{ }^{2}$ Because these are existing datasets, we did not determine sample size a prior. Instead, we included all available responses in both the ESS and EB. We report all data exclusions. The sample sizes, mean age, and gender distribution for each

\footnotetext{
${ }^{2}$ More waves from the EB are available, however, we only choose waves that include 10 or more items so that there are enough items for which to estimate consensus.
} 
country/wave combination are in tables linked from the online supplemental materials. This combination of data sources allows us to cover several decades of European history, with high quality samples of European countries, and measures of a wide range of political issues (see Measures).

\section{Measures}

Ondish and Stern used political attitudes, which defined reflecting participants' personal attitudes toward an issue and if the issue could be legislated on or voted on by the public. We used the same criteria. The authors combed through the materials for the ESS and EB to identify items and these were further checked by the first author. In some cases items were part of experiments embedded in the survey (e.g., the ESS periodically embedded vignette studies) and items related to these experiments were not included. For the ESS data, we identified 30 measures on average over the 9 waves, ranging from 13 in 2006 and 57 in 2002 . For the EB data, we identified 20 on average over the 34 waves, ranging from 10 in EB17 and EB29 and 31 in EB370.

We coded whether a country was in Eastern Europe (0) or not (1) based on whether the country was part of the former Eastern bloc. In the ESS, Germany was coded as not Eastern Europe. In the EB, Eastern and Western Germany were categorized as Eastern and non-Eastern respectively.

\section{Results}

\section{Analytic Strategy}

We follow the same analytic strategy as Ondish and Stern (2018), with some deviations to account for the different structure of our data (different countries in addition to different waves). First, we estimate consensus for leftists, rightists, and moderates using the one-with- 
many model from the Social Relations Model (Kenny, Kashy, \& Cook, 2006) which is designed to estimate how much people agree across many targets (i.e. attitudes). In practice, the model estimates the amount of variance attributable to the attitudes for each subset of participants (leftists, rightists, and moderates). We first standardize (z-scores) all of the attitude measures. Then we estimate intercept-only multilevel models with random intercepts for the attitude measures and for participants. We save the variance estimates from this model and then standardize the variance estimates due to the attitude measures relative to the total variance in the model. We do this for each subset of participants for each country/wave combination in each of the surveys to estimate consensus for each political group. This gives us the amount of shared variance (i.e. consensus) for leftists, rightists, and moderates across each country/wave combination. Consensus estimates per year for each ideological group are in Figures 1 and 2. 


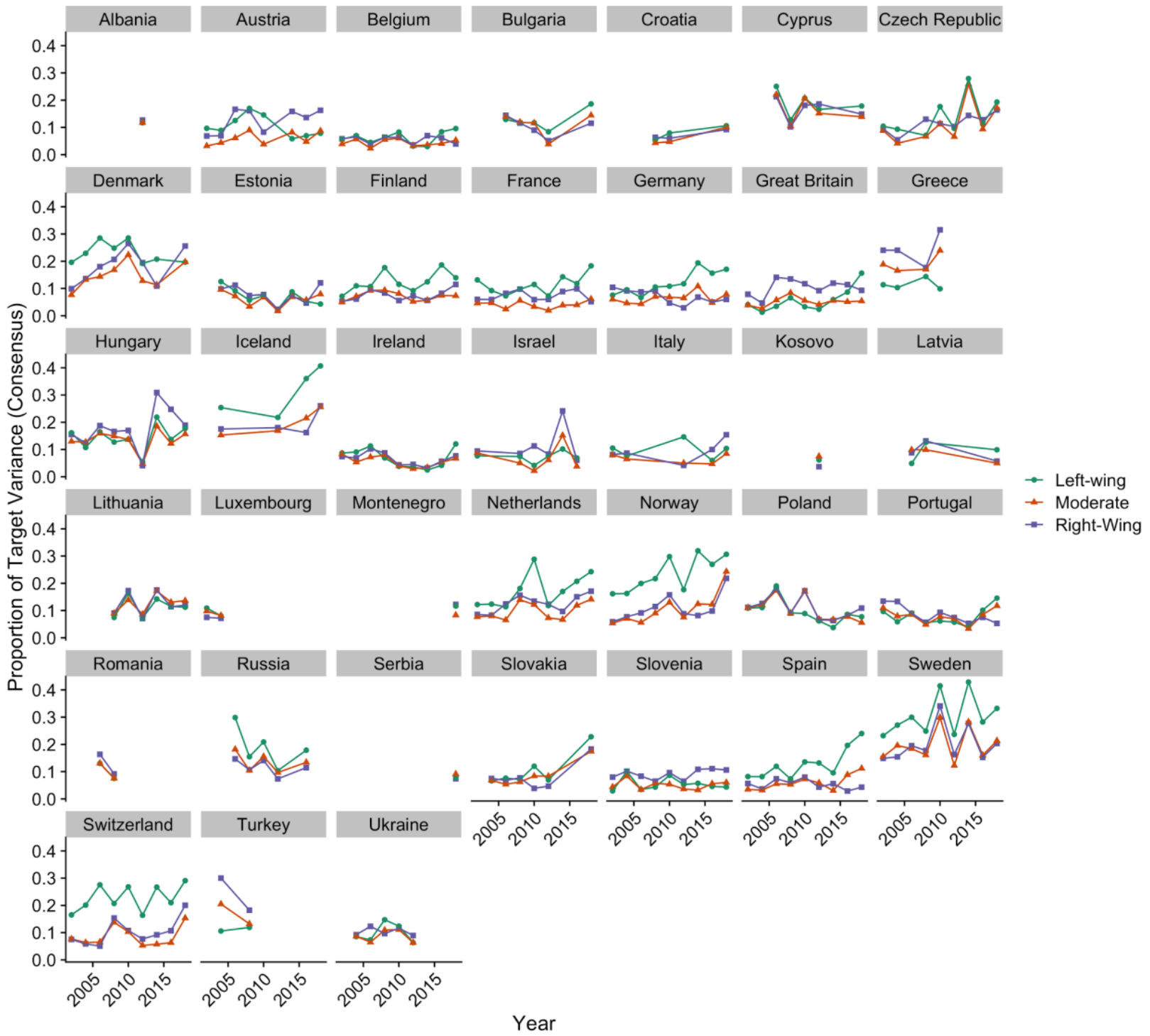

Figure 1. Estimates for consensus for each ideological group in each country for each wave of the European Social Survey. 


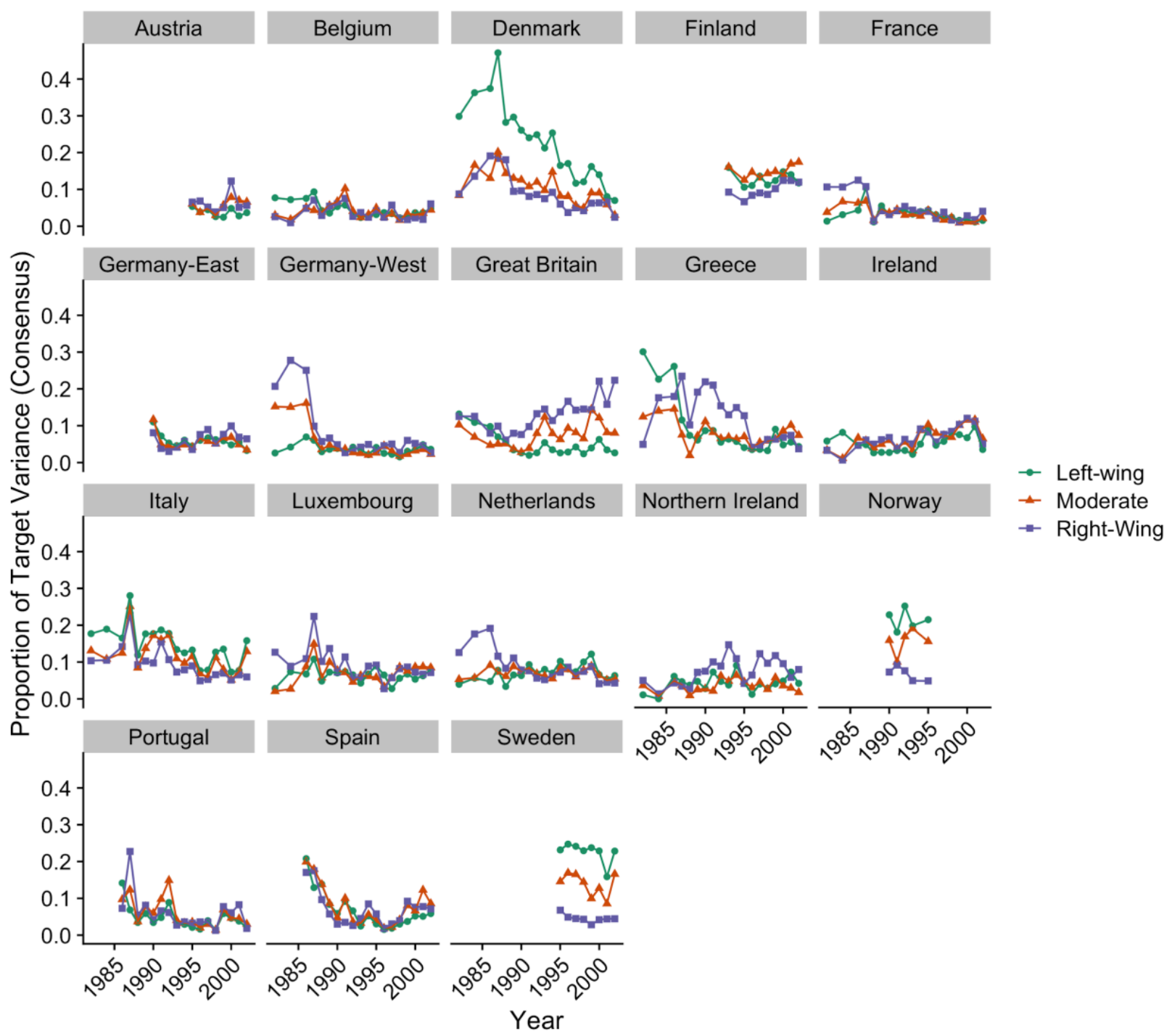

Figure 2. Mean estimates for consensus for each ideological group in each country for each year of the Eurobarometer. Because there are multiple waves per year, this figure reports the mean per year. Analyses treat each wave separately.

The estimates of consensus are our key outcome variable. Ondish and Stern (2018) regressed these estimates onto a moderate vs. liberal dummy code and a conservative vs. liberal dummy code using a multilevel model that nests consensus observations in waves. We use a similar approach by regressing consensus estimates onto a moderate vs left-wing dummy code (1 $=$ moderate, $0=$ left-wing $)$ and a right-wing vs. left-wing dummy code $(1=$ right-wing, $0=$ leftwing). We then estimated this basic model using a variety of different specifications (see Tables 
S1 and S2) that aim to account for nesting in country and survey wave. These specifications included multilevel models nesting consensus estimates in country and wave, multilevel models nesting consensus estimates in country and controlling for wave, and linear regression models that control for country and wave. Because we did not preregister the analyses and because there are multiple defensible choices, we ran them all and plot all of the results in Figures 3 and 4.

\section{Main Analyses}

The results were mixed. The analysis of the European Social Survey clearly conceptually replicated the liberal consensus effect in Europe. That is, there was support for a leftist consensus effect. Figure 3 shows that across all models, leftists had more consensus than moderates and across nearly all models leftists had more consensus than rightists. Moreover, the effect sizes were approximately the same size as those found by Ondish and Stern (2018). The three models with non-significant estimates for the difference between rightists and leftists are the three models that included random slopes for both of the dummy codes. The inclusion of both of these random slopes appears to have slightly reduced the size of the effect and substantially increased the variability, resulting in a non-significant difference that is nonetheless similar in size for the effect estimated in Ondish and Stern (2018) and the effect sizes from the remaining models. 


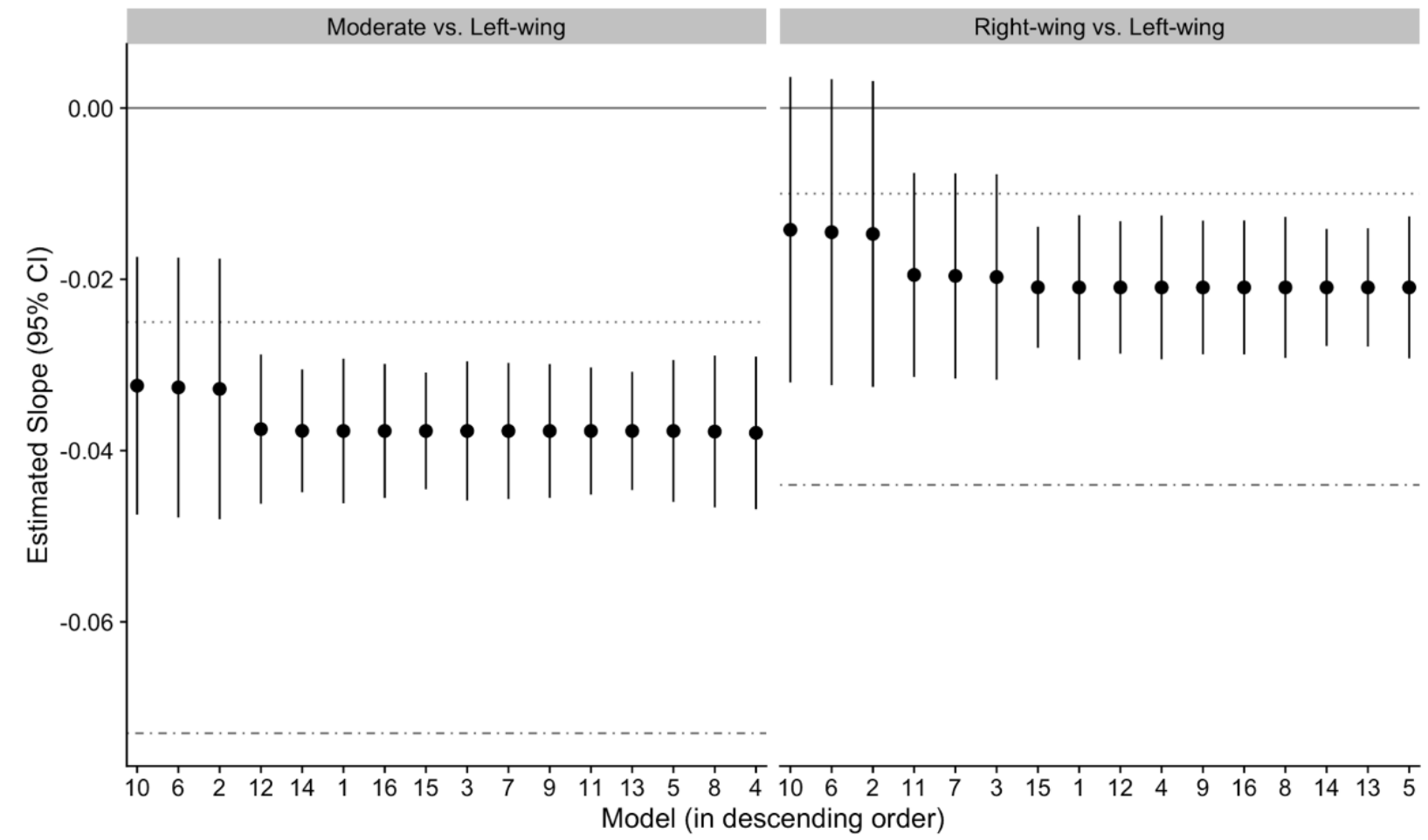

Figure 3. Estimated slope (and 95\% confidence interval) of the moderate vs. left-wing and the right-wing vs. left-wing comparisons for the European Social Survey. Estimates are ordered in decreasing order. Solid horizontal line is a null effect. The dotted horizontal line is the effect estimated in Study 1 of Ondish and Stern (2018). The dashed-dotted horizontal line is the effect estimated in Study 2 of Ondish and Stern (2018).

The analysis for the Eurobarometer, however, was not a clear conceptual replication.

Figure 4 shows that although there seems to be evidence that leftists have more consensus than moderates (as expected), the difference between leftists and rightists was never significant and, in most cases, the confidence intervals did not overlap with the original effect sizes from Ondish and Stern (2018). At the same time, the largest of the estimates are larger than at least one of the estimates from Ondish and Stern (2018), but the confidence intervals are quite large making it impossible to rule out an effect in the opposite direction nor a larger effect consistent with the hypothesis. 


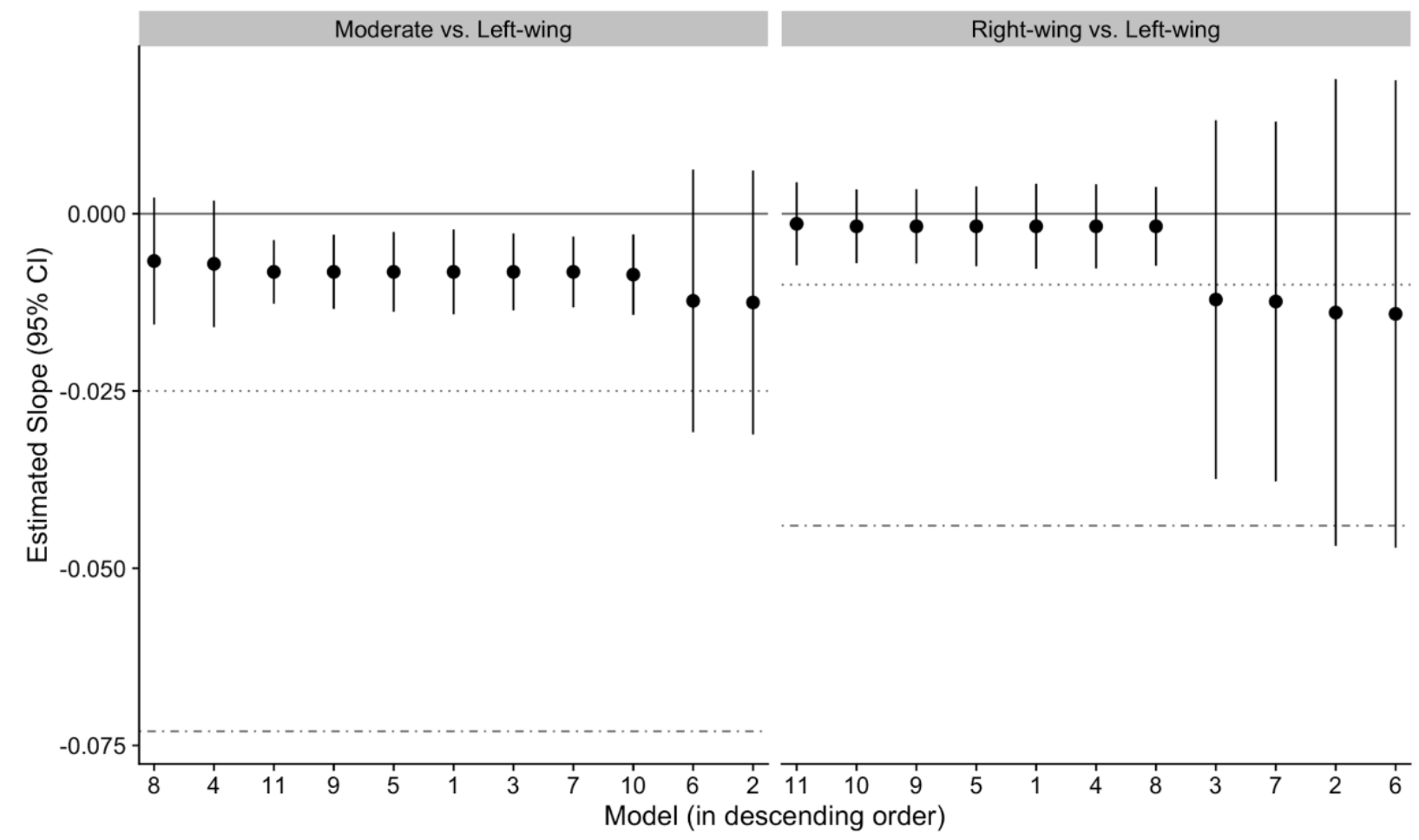

Figure 4. Estimated slope (and 95\% confidence interval) of the moderate vs. left-wing and the right-wing vs. left-wing comparisons for Eurobarometer. Estimates are ordered in decreasing order. Solid horizontal line is a null effect. The dotted horizontal line is the effect estimated in Study 1 of Ondish and Stern (2018). The dashed-dotted horizontal line is the effect estimated in Study 2 of Ondish and Stern (2018).

\section{Variability Analysis}

One advantage of including multiple countries and adopting a multilevel modeling approach for many of our tested models is that we can test if there is variability in the size of the effect. There is. All but two of the random slopes are significant $(p<.05)$ across all of the ESS models and all of the random slopes are significant $(p<.05)$ across all of the EB models. We extracted the estimates for each country (or country/wave combination for the more complexly nested models) from models that included the necessary random slopes. Figures 5 and 6 report those estimated effects across all of the models. They show that both surveys contain instances of a leftist consensus effect (negative slopes) that exceed the size of the effects found in Ondish and Stern's (2018) analysis of the U.S. Both surveys also contain instances of a rightist consensus 
effect (positive slopes) when comparing rightists vs leftists. Although the leftist consensus effect is dominant in the European Social Survey (resulting in the clear replication above), both a leftist and a rightist consensus effect is present in the Eurobarometer. This variability in the emergence of the leftist consensus effect, however, was not explained by whether or not the country was in Eastern Europe (see online supplemental materials). 

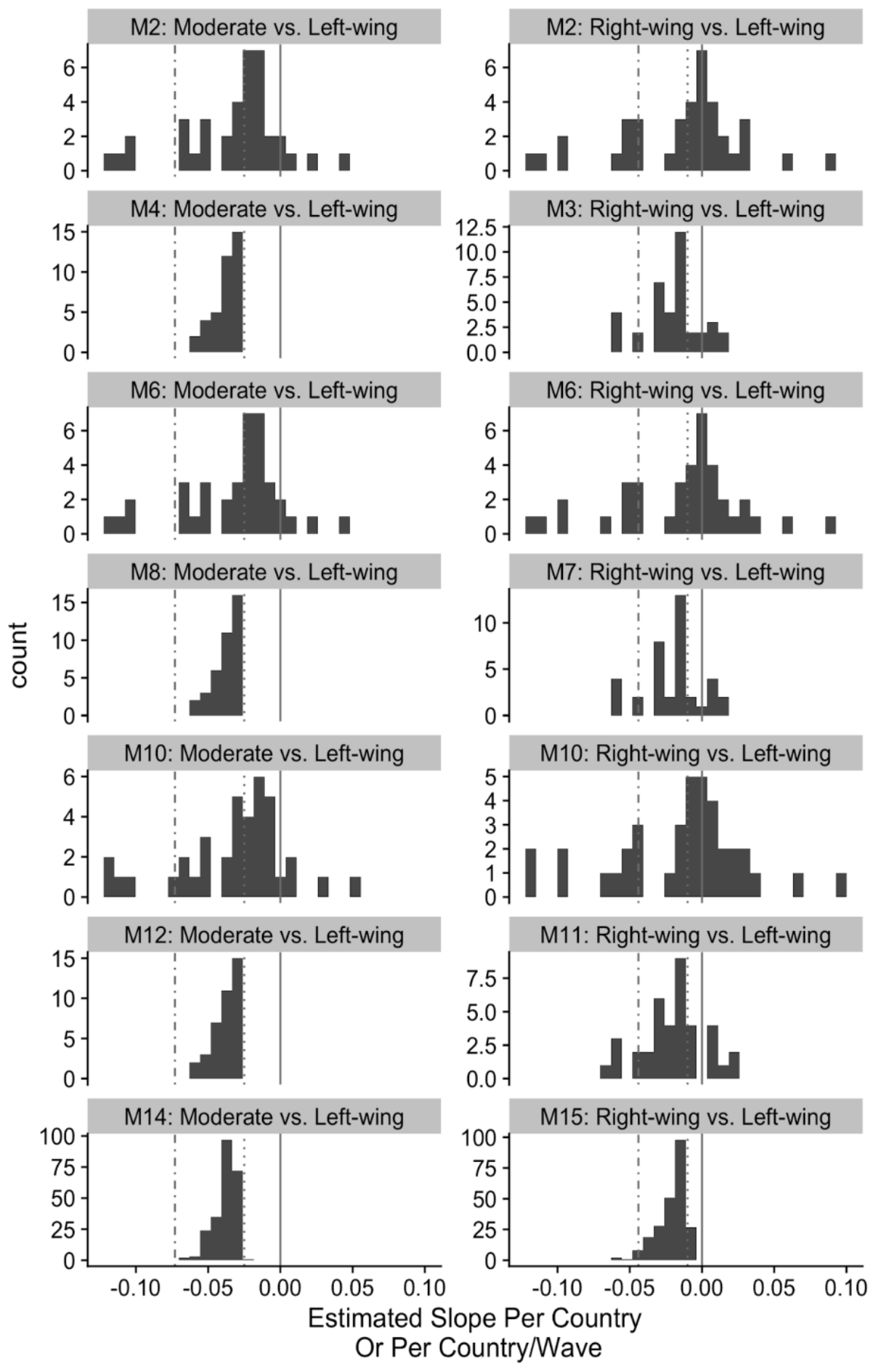

Figure 5. Estimated slope for each country or each country/wave of the European Social Survey. Models 4 and 14 were the only models without significant variation in their slopes ( $p>.05$ ). Solid vertical line is a null effect. The dotted vertical line is the effect estimated in Study 1 of Ondish and Stern (2018). The dashed-dotted vertical line is the effect estimated in Study 2 of Ondish and Stern (2018). 


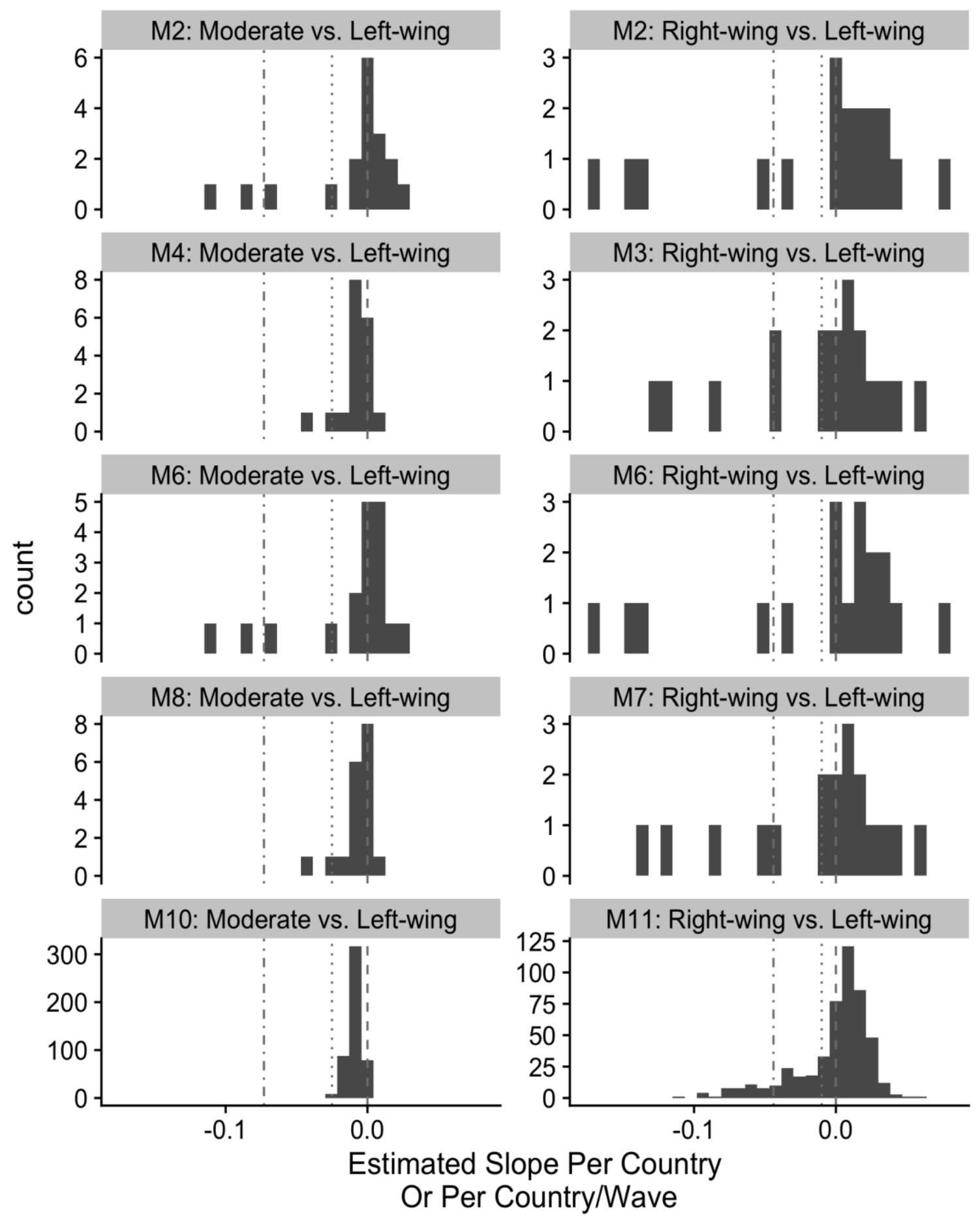

Figure 6. Estimated slope for each country of the Eurobarometer. All models had significant variation in slopes. Solid vertical line is a null effect. The dotted vertical line is the effect estimated in Study 1 of Ondish and Stern (2018). The dashed-dotted vertical line is the effect estimated in Study 2 of Ondish and Stern (2018). 


\section{Discussion}

We found evidence for a leftist consensus effect in the European Social Survey (ESS) that conceptually replicates the liberal consensus effect previously found in the United States (Ondish \& Stern, 2018). This leftist consensus effect did vary in size (and sometimes direction) across countries, but this variation was not explained by whether or not the country was in Eastern Europe. We did not find evidence for a leftist consensus effect in the Eurobarometer (EB). Some countries seemed to show such an effect, whereas others seemed to show the opposite effect. This variation was not explained by whether or not the country was in Eastern Europe.

The clear replication in the ESS compared to the small and more ambiguous results from the EB raises the question of what explains the difference. One possibility is that this is just random variation that happens from study to study by way of chance. There are at least two substantive differences that might also explain the difference. First, the ESS included a broader range of measures that cover a wider variety of topics. The EB primarily focused on issues of European integration (see tables linked in the supplemental materials), which may have different ideological and consensus dynamics than other issues. This suggests that any liberal or leftist consensus effect may not be relevant to some issue domains and is consistent with Hanel and colleagues (2019) observation that the levels of heterogeneity varied across different values. Second, the ESS included more countries than the EB and these additional countries may have shown larger leftist consensus effects than the countries that are shared with the EB.

This second substantive difference appears unlikely. We conducted additional analyses comparing the consensus effects for countries that were similar or different between the two surveys. We found that the absolute values of the mean difference between leftist consensus and 
rightist consensus estimates in the ESS was larger for countries the two surveys shared $(\mathrm{M}=$ $.022)$ than those that were only available in the ESS $(M=-.007)$. This would seem to suggest that the EB should show larger effects than the ESS. We also found that the difference between leftist and rightist estimates for each country in the ESS were correlated with these same estimates from the same countries in the $\mathrm{EB}, r(13)=.72, \mathrm{p}=.002$ (see Figure $\mathrm{S} 3$ ). $73 \%$ of the differences between leftist and rightist estimates were in the same direction for both the ESS and the EB, suggesting some degree of internal replication. Overall, this suggests that although the leftist consensus effect in the ESS is larger than the effect in the EB, the results in the two survey results do correspond. It may then be the case that the different topics covered by the EB resulted in a smaller effect size.

Our study, like Ondish and Stern's (2018) original work, cannot speak to the precise mechanisms that lead to it. The mechanism thought to cause the liberal consensus effect relied on the different motivations that liberals and conservatives are thought to experience. Building on this idea and work that finds the link between psychological motivations and ideological identification differs between Eastern and Western Europe, we thought that the leftist consensus effect might be most prevalent outside of Eastern Europe. As detailed in the online supplemental materials, this was not the case. This could indicate that different psychological motivations are not responsible for the leftist consensus effect. This conclusion, however, is likely premature. For example, it is possible that we did not observe a significant moderation by region because there are relatively few observations in each region. Another possibility is that the motivations that lead to the leftist consensus effect are the motivations that have similar effects across regions (cf. the results for rule following in Thorisdottir et al., 2007). Regardless of the reason, more direct tests of the process that give rise to the liberal and leftist consensus effects are necessary. 
The results from the European Social Survey are likely to generalize to analyses of European countries that include a wide variety of issues. We are unsure how or if the results of the Eurobarometer will generalize. Notably, we did observe significant variation across countries and therefore the estimates we report are the average estimates across the countries we included. Before assuming that a leftist consensus effect will emerge in any of the countries included in our work, we suggest that the estimates from our study be consulted. This also means that it is not known whether these results will replicate in countries that do not have the same history of left-wing and right-wing ideological identification (e.g., countries in Africa, Asia). ${ }^{3}$ At this time, it appears that there is evidence for a liberal consensus effect in the United States (Ondish \& Stern, 2018) and a leftist consensus in Europe when assessing a wide range of issues. This is consistent with suggestions that ideological identification operates similarly (although not identically) in Europe and the United States.

\footnotetext{
${ }^{3}$ For work on ideology in China see Pan and $\mathrm{Xu}$ (2018). For work on ideology in India see Puthillam, Kapoor, and Karandikar (2021).
} 


\section{References}

Barberá, P., Jost, J. T., Nagler, J., Tucker, J. A., \& Bonneau, R. (2015). Tweeting from left to right: Is online political communication more than an echo chamber? Psychological Science, 26, 1531-1542.

Bauer, P. C., Barberá, P., Ackermann, K., \& Venetz, A. (2017). Is the left-right scale a valid measure of ideology? Political Behavior, 39, 553-583.

Bolger, N., Zee, K. S., Rossignac-Milon, M., \& Hassin, R. R. (2019). Causal processes in psychology are heterogeneous. Journal of Experimental Psychology: General, 148, 601618.

Boutyline, A., \& Willer, R. (2017). The social structure of political echo chambers: Variation in ideological homophily in online net- works. Political Psychology, 38, 551-569.

Brandt, M., \& Sleegers, W. (2021). Evaluating belief system networks as a theory of political belief system dynamics. Personality and Social Psychology Review, 25, 159-185.

Brandt, M. J., Turner-Zwinkels, F. M., Karapirinler, B., Van Leeuwen, F., Bender, M., van Osch, Y., \& Adams, B. (2021). The association between threat and politics depends on the type of threat, the political domain, and the country. Personality and Social Psychology Bulletin, 47, 324-343.

Caprara, G. V., \& Vecchione, M. (2018). On the left and right ideological divide: Historical accounts and contemporary perspectives. Political Psychology, 39, 49-83.

Chirumbolo, A., Areni, A., \& Sensales, G. (2004). Need for cognitive closure and politics: Voting, political attitudes and attributional style. International Journal of Psychology, 39, 245-253.

Ellis, C., \& Stimson, J. A. (2012). Ideology in America. Cambridge University Press. 
European Social Survey (2018). European Social Survey Round 9 Data (Edition 3.1) [Data set].

Norwegian Centre for Research Data, Norway. doi:10.21338/NSD-ESS9-2018.

European Social Survey (2016). European Social Survey Round 8 Data (Edition 2.2) [Data set].

Norwegian Centre for Research Data, Norway. doi:10.21338/NSD-ESS8-2016.

European Social Survey (2014). European Social Survey Round 7 Data (Edition 2.2) [Data set].

Norwegian Centre for Research Data, Norway. doi:10.21338/NSD-ESS7-2014.

European Social Survey (2012). European Social Survey Round 6 Data (Edition 2.4) [Data set].

Norwegian Centre for Research Data, Norway. doi:10.21338/NSD-ESS6-2012.

European Social Survey (2010). European Social Survey Round 5 Data (Edition 3.4) [Data set].

Norwegian Centre for Research Data, Norway. doi:10.21338/NSD-ESS5-2010.

European Social Survey (2008). European Social Survey Round 4 Data (Edition 4.5) [Data set].

Norwegian Centre for Research Data, Norway. doi:10.21338/NSD-ESS4-2008.

European Social Survey (2006). European Social Survey Round 3 Data (Edition 3.7) [Data set].

Norwegian Centre for Research Data, Norway. doi:10.21338/NSD-ESS3-2006.

European Social Survey (2004). European Social Survey Round 2 Data (Edition 3.6) [Data set].

Norwegian Centre for Research Data, Norway. doi:10.21338/NSD-ESS2-2004.

European Social Survey (2002). European Social Survey Round 1 Data (Edition 6.6) [Data set].

Norwegian Centre for Research Data, Norway. doi:10.21338/NSD-ESS1-2002.

Feldman, S., \& Johnston, C. (2014). Understanding the determinants of political ideology:

Implications of structural complexity. Political Psychology, 35, 337-358.

Gidron, N. (in press). Many ways to be right: cross-pressured voters in Western Europe. British Journal of Political Science. 
Hanel, P. H., Zarzeczna, N., \& Haddock, G. (2019). Sharing the same political ideology yet endorsing different values: left-and right-wing political supporters are more heterogeneous than moderates. Social Psychological and Personality Science, 10, 874882.

Henrich, J., \& Boyd, R. (1998). The evolution of conformist transmission and the emergence of between-group differences. Evolution and Human Behavior, 19, 215-241.

Jost, J. T., Krochik, M., Gaucher, D., \& Hennes, E. P. (2009). Can a psychological theory of ideological differences explain contextual variability in the contents of political attitudes?. Psychological Inquiry, 20, 183-188.

Jost, J. T., Sterling, J., \& Stern, C. (2017). Getting closure on conservatism, or the politics of epistemic and existential motivation. In C. Kopetz \& A. Fishbach (Eds.), The motivationcognition interface, from the lab to the real world: A festschrift in honor of Arie W. Kruglanski. Routledge.

Kenny, D. A., Kashy, D. A., \& Cook, W. L. (2006). Dyadic data analysis. New York, NY: Guilford Press.

Knutsen, O. R. (1998). Expert judgements of the left-right location of political parties: A comparative longitudinal study. West European Politics, 21, 63-94.

Kossowska, M., \& van Hiel, A. V. (2003). The relationship between need for closure and conservative beliefs in Western and Eastern Europe. Political Psychology, 24, 501-518.

Lupton, R. N., Myers, W. M., \& Thornton, J. R. (2017). Party animals: asymmetric ideological constraint among Democratic and Republican Party activists. Political Research Quarterly, 70, 889-904. 
Malka, A., Soto, C. J., Inzlicht, M., \& Lelkes, Y. (2014). Do needs for security and certainty predict cultural and economic conservatism? A cross-national analysis. Journal of Personality and Social Psychology, 106, 1031-1051.

Mason, L. (2018). Losing common ground: Social sorting and polarization. The Forum, 16, 4766.

Ondish, P., \& Stern, C. (2018). Liberals possess more national consensus on political attitudes in the United States: An examination across 40 years. Social Psychological and Personality Science, 9, 935-943.

Pan, J., \& Xu, Y. (2018). China's ideological spectrum. The Journal of Politics, 80, 254-273.

Puthillam, A., Kapoor, H., \& Karandikar, S. (2021). Beyond left and fight: A scale to measure political ideology in India. https://doi.org/10.31234/osf.io/fg387

Thorisdottir, H., Jost, J. T., Liviatan, I., \& Shrout, P. E. (2007). Psychological needs and values underlying left-right political orientation: Cross-national evidence from Eastern and Western Europe. Public Opinion Quarterly, 71, 175-203.

Schmitt, H. \& Scholz, E. (2005). The Mannheim Eurobarometer trend File, 1970-2002. (ICPSR 4357; Version V1) [Data set]. ICPSR. https://doi.org/10.3886/ICPSR04357.v1 Stenner, K. (2005). The authoritarian dynamic. Cambridge University Press.

Stern, C., West, T. V., \& Schmitt, P. G. (2014). The liberal illusion of uniqueness. Psychological Science, 25, 137-144.

Van Hiel, A. (2012). A psycho-political profile of party activists and left-wing and right-wing extremists. European Journal of Political Research, 51, 166-203. 
Whitsett, D. D., \& Shoda,Y. (2014).An approach to test for individual differences in the effects of situations without using moderator variables. Journal of Experimental Social Psychology, 50, 94-104. 